\title{
Modeling the Filling Rate of Faeces in Ordinary Pit Latrines
}

\author{
Ugwu Francis Ifeuzu, Agunwamba Jonah Chukwuemeka
}

\begin{abstract}
Faecal sludge deposited into the pit latrine is subject to biodegradation. The aim of this research was to develop model for the filling rate of faeces in ordinary pit latrine together with the effect of shape factor on such fillings to prepare the minds of users on the filling characteristics of the pit based on contents, usage and environmental factors. Consequently, faecal sludges sampled from 100 pits already filled were subjected to laboratory analyses for their physico-chemical and biological characteristics. Models for the actual filling rate of faeces in ordinary pit latrines were derived using BOD, COD, VS, and TS data, calibrated and verified. For a more critical situation, models were also derived for the filling rates considering pit shapes that gave the actual pit filling in comparison with the general condition. From the results, the actual filling rate was lower than those obtained using BOD, VS and TS. However, the COD gave filling rate closer to the actual filling rate than other parameters since TS could not be used to assess the filling rate of faeces in pit latrines. The pits exhibited low filling rate in terms of $B O D$ in 2 pits. In terms of COD, the filling rate was higher compared with that of $B O D$. Low filling rate was observed with volatile solids and only 3 pits exhibited moderately high filling rates whereas total solids had the highest number of pits with high filling rates. The filling rates for both the square and rectangular pits increased by $26.5 \%$ from $40-90$ //capita/year to $50-112$ //capita/year due to the shape factor and this was above the values obtained in existing models while that of the circular pit remained the same. Reduction in pit volume and increase in filling rate by faeces was due to dead corners as a result of clogging, thereby reducing the area available for faecal infiltration into the surrounding soil. Circular pits are more stable because of the natural arching effect of the ground around the hole and there are no corners to concentrate the stresses. Pits with flat sides are much more likely to develop clogging resulting to dead corners than the circular pit. From this study, it is therefore evident that the shape of pit latrine determines the actual volume and the filling rate of faeces in pit latrine taking into consideration geological and environmental factors. Thus for optimal design, our engineers should take note of the pit shape factor. Thus, the model can be used to determine the filling rate of ordinary pit latrines considering soil characteristics, ground conditions and other favourable conditions.
\end{abstract}

Keywords: Faecal sludge; pit latrine; biodegradation; filling rate; filling characteristics; environmental factors; physicochemical and environmental characteristics; favourable conditions; shape factor; latrine shapes; absorption system; dead corners; effective cross-sectional area, optimal pit latrine design.

Manuscript received on 14 April 2021 | Revised Manuscript received on 17 May 2021 | Manuscript Accepted on 15 May 2021 | Manuscript published on 30 May 2021.

* Correspondence Author

Ugwu Francis Ifeuzu*, Department of Civil Engineering, University of Nigeria, Nsukka. E-mail.ugwufrancisifeuzu@yahoo.com

Prof. Agunwamba Jonah Chukwuemeka, Department of Civil Engineering, University of Nigeria, Nsukka. e-mail. Jonah.Agunwamba@unn.edu.ng

(C) The Authors. Published by Lattice Science Publication (LSP). This is an open access article under the CC-BY-NC-ND license (http://creativecommons.org/licenses/by-nc-nd/4.0/)

\section{INTRODUCTION}

Excreta deposited into a pit latrine is subject to some level of biodegradation which substantially reduces the volume of the sludge. On the other hand, other materials that are not biodegradable usually find their way into the pit, thus affecting their filling rates. The net filling rate of the pit is thus dependent on both the rate of addition of material and its composition.

Several factors impact the key processes within a pit latrine which determine the rate at which it will fill. Filling rate depends on the addition of new material into the pit, the transfer of water into and out of the pit, biological transformations, and bacteria die-off (Buckley et al., 2008). A standard pit generally contains a range of materials, including faeces, urine, cleansing material and general solid waste. In the pit surface, aerobic degradation occurs. As sludge is covered over with fresh material and no longer has contact with the air, anaerobic degradation takes over.

This research therefore was relevant as it sought to derive accurate and reliable models for the filling rate of faeces in pit latrines using field data and data obtained from laboratory analyses of faecal sludge samples collected from 100 pit latrines in Aku, the study community.

\section{LITERATURE REVIEW}

Available literatures on the processes occurring inside a pit latrine are limited. The main function of the pit (the substructure), apart from serving as reservoir of faecal matter, is to treat and filter the effluent into the ground. Information on the rate of pit filling is documented (Mara, 1984). Storage duration affects the filling rate of the pit latrines. The filling rate and storage duration depend on the type of technology, quality of construction, toilet usage, and inflow and infiltration. The pit, if well operated contains faeces, urine, anal cleansing material and/or anal cleansing water (Foxon et al., 2008; Buckley et al., 2008). The rate at which the latrine fills then depends partly on the rate of addition of faeces and partly on the rate of degradation. If systems are permeable, the amount of inflow and infiltration will be influenced by the type of soil and the groundwater level. The Pollution Research Group of the University of Kwazulu, Natal, South Africa considered in one of their researches what human excreta consisted of (Nwaneri et al, 2008). They found out that, on the average, people excrete 1.5 litres of urine per person per day and $0.4 \mathrm{~kg}$ of faeces per person per day.

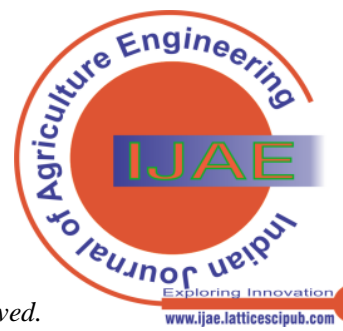




\section{Modeling the Filling Rate of Faeces in Ordinary Pit Latrines}

User-behaviour affects the make-up of faeces, the volume of urine that goes into the pit, the presence of solid or liquid waste in the pit and the presence of chemical or biological agents in the pit which could suppress or enhance degradation.

\subsection{Factors affecting the filling rate of faeces in pit latrines}

The shape of any pit latrine depends on user's choice and the nature of the local soil. Pit shape influences the velocity of flow through it, the depth of accumulation of sludge, and the presence or absence of dead corners. The filling rate of faeces in pit latrine is a function of so many factors including the population of users, nature of the soil, the level of groundwater and the material for anal cleansing which is particularly important.

\subsubsection{Decomposition Processes in Pit Latrine}

The sludge decomposes in one of two ways, aerobic and anaerobic. Generally, aerobic decomposition is a faster process than the anaerobic decomposition. Anaerobic digestion produces fewer bugs as lots of the organic components are turned to methane (Foxon et al., 2008).

Several factors affect anaerobic decomposition in pit latrines. One of such factors is temperature which influences the rates of enzymatically catalyzed reactions and also affects the rate of diffusion of substances into the cell (Grady et al., 1999). Temperature affects the concentrations of various inhibitory substances found in anaerobic processes (Chen et al., 2008). Another factor is the total solids concentration of faecal sludge that comes from a variety of organic (volatile) and inorganic (fixed) matter (floating material, settleable matter, colloidal material, and matter in solution). The ratio of VS to TS is used as an indicator of the relative amount of organic matter and the biochemical stability of faecal sludge. Martin et al (2003) showed that minimum moisture content is necessary to facilitate mass transfer by promoting the diffusion of substances to, and waste products away from, microorganisms, leading to a better biodegradation rate. Bhagwan et al (2008) suggested that if a system is so dry, there will be problems due to viscosity and osmotic pressure limitations, and if there is an excess of water in a draining environment, it would allow soluble substances to leach from the pit, possibly slowing down the biological process. Couderc (2008) observed some correlation between the moisture content and faecal degradation and suggested that for biodegradation to be effective, adequate moisture must be available in the system.

\subsubsection{Characteristics of the Surrounding Soil}

Geological characteristics of the surrounding soil where the pit latrines are placed can have an important influence in the processes happening inside the pit (Bhagwan et al., 2008). Soil permeability and porosity determine the filling time required and is the primary determinant of the absorption capacity of the soil. It was found out that since the infiltrative capacity of the soils varied, that it was important to determine the infiltrative capacity of the particular soil before designing pit latrine. Percolation rates have been used to grade the suitability of soils for latrine construction with respect to the absorption system. When the hydraulic conductivity is low, it leads to very poor infiltration, but when excessive, leads to insufficient purification of the effluent. Very steep slopes impair the capability of the land to dispose effluent effectively and efficiently too (Bouma, 1974; Coutera et al., 1979). The depth of Water Table (WT) also affects the rate of flow of effluent from the system, especially vertical flow. A shallow groundwater table may cause insufficient infiltration, and surfacing of unpurified effluent (Bouma et al., 1981).

Pit latrine filling is currently a problem associated with their performance. The available information indicates that pit latrines are mainly filling faster than expected and this is attributed to the rate of sludge accumulates within the pit.

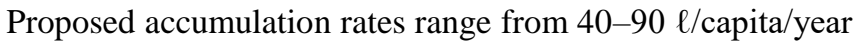
(Franceys et al., 1992; Wagner et al, 1958). More recent field investigations undertaken in peri-urban South Africa by Norris (2000) found lower rates and thus proposed 25.5 $\ell /$ capita/year. In their study by Still et al. (2002) in South Africa, sludge accumulation rates were found to range

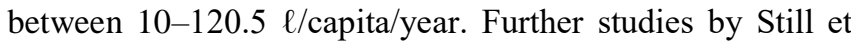
al., (2002) noted filling rates of 1-264 $\ell$ /capita/year. Available data indicate variable pit latrine sludge accumulation/filling rates by region, even in a comparatively homogeneous environment.

Several factors affect the filling rate of faeces in pit latrine. Lopez et al., (2004) studied the effect of temperature on aerobic biodegradation of faeces in the bio-toilet system and showed that the optimum temperature for improving faecal biodegradability is within the thermophilic range, $60^{\circ} \mathrm{C}$ $70^{\circ} \mathrm{C}$. The $\mathrm{pH}$ value also affects the filling rate of faeces in pit latrine and should be within a range of $6.5-8$. (Bhagwan et al., 2008). Moisture content studied by Martin et al. (2003) showed that minimum moisture content is necessary to facilitate mass transfer by promoting the diffusion of substances to, and waste products away from, microorganisms, leading to a better biodegradation rate. Geological characteristics of the surrounding soil such as permeability, natural moisture content, percolation rate, particle size distribution, infiltration capacity and long-term acceptance rates, topography of the site where the pit latrines are placed can have an important influence in the processes happening inside the pit (Bhagwan et al., 2008; Bouma, 1974; Coteral et al., 1979). Throwing rubbish into a pit almost doubled its filling rate in studies undertaken in South Africa (Still et al., 2012; Buckley et al.; 2008). Decreasing degradation rate due to developed dead corners as the pit fills results in pits filling faster than degradation occurs.

\subsection{Shape of the Pit Latrine}

The best shape for a pit is circular since is more stable due to the natural arching effect of the ground around the hole and there are no corners to concentrate the stresses. For the same volume, a wide shallow pit will fill more quickly than a deep narrow pit. This is because the top $0.3 \mathrm{~m}$ of the pit is not used and so is effectively wasted. The shape affects the pit filling rate due to dead corners as a result of clogging the sides of the pits limiting infiltrative capacity of the soil. Shape-factor, $\mathrm{S}_{\mathrm{f}}$, can be expressed as

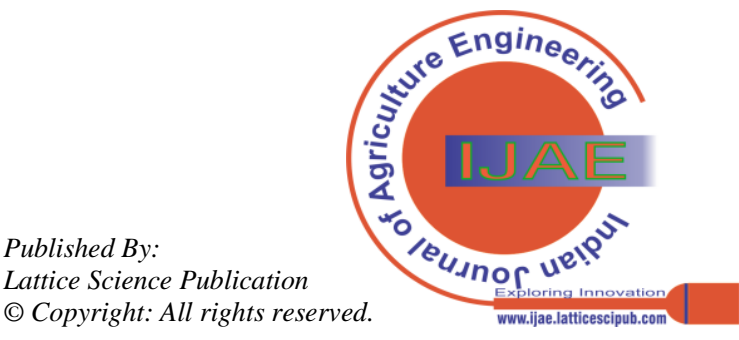


$S f=\frac{\text { effective settling area }}{\text { Total Area }}$

As the pits start filling, dead corners begin to develop. The effective settling area of faeces is visualized as those occupied by the circle and ellipse for square, circle and rectangular pit respectively.

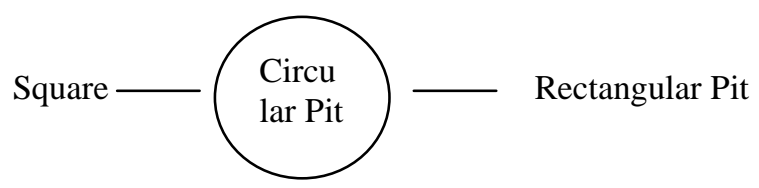

\section{MATERIALS AND METHOD}

This research started with the administration of questionnaires to one hundred (100) households of the study community to collect information on user population, latrine shapes and dimensions, soil type and ground condition, faecal samples using sampler, frequency of defecation, soilseal depths of filled latrines and age of the pit latrines The research went further to derive model for the general filling rate irrespective of pit shape as well as considering shape factor on different pit shapes. The 100 household pit latrines sampled in this study are scattered within the study area. The filling model was then developed and verified using the laboratory data obtained from above.

\subsection{Samples Collection}

One hundred (100) pit latrines in the selected community were sampled using a well designed sampler. Samples from were taken across each pit layer to allow for heterogeneity of the contents. Samples from the first pit latrine were collected in $2^{\text {nd }}$ April, 2013. Subsequent samples were collected at the intervals of 2 weeks in the other pits to allow enough time for the analysis of previous samples collected. The last set was collected in July, 2013. Second sets of samples were collected after 5 months in January, February, March and April, 2014 at closer intervals of 1 month. Samples were collected while avoiding much suspended solids often associated with this type of latrine. In each of the pit latrines, samples were collected at six different vertical intervals namely at the surface layer and at $0.2 \mathrm{~m}$, $0.4 \mathrm{~m}, 0.6 \mathrm{~m}, 0.8 \mathrm{~m}$ and $1.0 \mathrm{~m}$ depths below the surface and analyzed. These intervals were to find out more about the levels of degradation within shorter vertical intervals in the sludge mass.

\subsection{General Modeling of Pit Filling Rates.}

A basic principle of Chemical Engineering is that mass can neither be created nor destroyed.

This guiding principle permits us to understand what happens in the pit latrines and how fast they take to fill. Thus the general word statement is:

Inflow - Reaction - Outflow = Accumulation (3.0)

The materials mass-balance is diagrammatically represented in Diagram 3.1 as follows fluent, $\mathrm{M}(\mathrm{kg})$

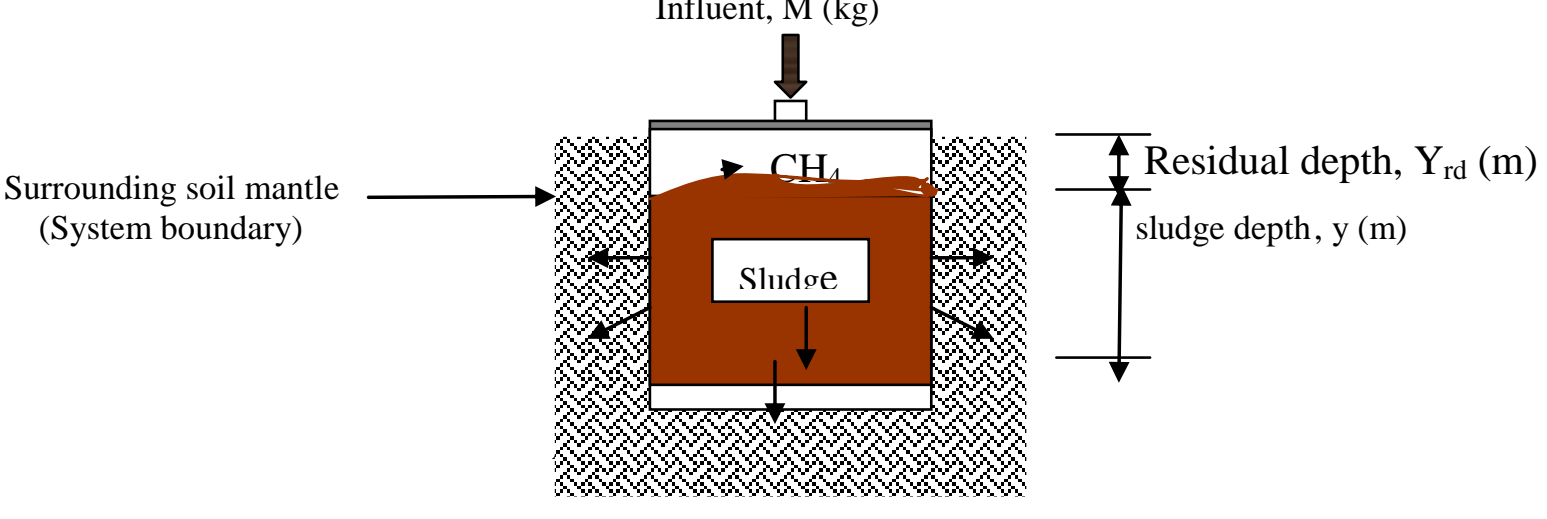

\section{Diag.3.1. Mass Balance of Solids in the Pit latrine}

Inflow consists of addition of urine and faeces, anal cleansing material, water for cleaning, detergents and disinfectants, rubbish, etc into the pit latrine. Outflow consists of drainage from the pit along with any solids dissolved in this outflow. Accumulation is therefore due to a build-up of bugs, salts, non-biodegradable matter (including rubbish), plus some undegraded but potentially biodegradable material.

To apply the mass-balance analysis to the sewage contents of the pit latrine, it was assumed that

- The feed characteristics and feed addition rate are constant and that biodegradable material all degrade at a single constant rate;

- the faecal sludge within the pit is not subject to evaporation;

- $\quad$ the faecal sludge within the pit is not mixed and each layer is peculiar to the excreta deposited by the users within specified time of latrine usage;
- a chemical reaction involving the faecal material is occurring within the pit; and

- $\quad$ the rate of change in mass of faecal sludge, $M$, that is occurring within the pit is governed by a first-order reaction;

- The inflow and outflow of moisture into the pit are equal and balance up.

Modeling here is on mass basis since the pit is called dry pit and faecal sludge is better measured in terms of mass.

Let us consider a mass of influent sludge which initially consists of material that is

$\begin{array}{lll}\text { biodegradable } & \text { let } \\ = & M_{b m}(i n k g)\end{array}$ it 


\section{Modeling the Filling Rate of Faeces in Ordinary Pit Latrines}

Let the unbiodegradable portion of the material be $=M_{u m}($ in $k g)$

Each $\mathrm{kg}$ of biodegradable material degrades to form mass of new unbiodegradable material designated as

$=k($ in $k g)$.

Mass of new unbiodegradable material is represented as

with

$$
\stackrel{\text { initial }}{M_{n m}=0}
$$

value

This degradation was modeled as $1^{\text {st }}$ order reaction with rate

$$
\frac{d M_{b}}{d \theta}=-\mathrm{r} \cdot \mathrm{M}_{\mathrm{b}}
$$

where $\mathrm{r}$ is the rate constant $\left(\mathrm{d}^{-1}\right)$

After the material has remained in the pit for time $\theta$, the unbiodegradable material

formed by degradation is

$\operatorname{Mn}(\theta)=k M b\left(1-e^{-r \theta}\right)$

and the original unbiodegradable material present is

$$
M u(\theta)=\text { Mum }
$$

The total mass present at age $\theta$ is

$$
\begin{aligned}
M(\theta) & =M b(\theta)+M n(\theta)+M u(\theta) \\
& =M b m e-r \theta+k M m o\left(1-e^{-r \theta}\right)+M u m \\
& =M u m+k M b m+(1-k) M b m e e^{-r \theta}
\end{aligned}
$$

The ratio of total mass present to original unbiodegradable material is:

$$
\begin{gathered}
\emptyset(\theta)= \\
=1+\frac{M(\theta)}{M_{u}(\theta)}=\frac{M(\theta)}{M_{u m}} \quad=\frac{M_{u m}+k M_{b m}+(1-k) M_{b m} e^{-r \theta}}{M_{u m}}+\frac{(1-k) M_{b m}}{M_{u m}} e^{-r \theta} \\
=1
\end{gathered}
$$

$$
\begin{aligned}
& \beta(\theta)=\frac{M_{b m}(\theta)}{M_{u m}(\theta)}=\frac{M_{b m} e^{-r \theta}}{m_{u m}+k M_{b m}+(1-k) M_{b m} e^{-r \theta}} \\
& =\frac{\left(M_{b m} / M_{u m}\right) e^{-r \theta}}{1+k\left(M_{b m} / M_{u m}\right)+(1-k)\left(M_{b m} / M_{u m}\right) e^{-r \theta}}
\end{aligned}
$$

Ash content is measured on a mass fraction basis and is a sub-fraction of the originally unbiodegradable fraction.

The mass of ash associated with $M(\theta)$ is $M_{a}=x M_{u m}$

The mass contained in $M(\theta)$ is

$$
\begin{aligned}
M(\theta) & =x M_{u m}+(1-x) M_{u m}+k M_{b m}+(1-k) M_{b m} e^{-r \theta} \\
& =x M_{u m}+(1-x) M_{u m}+k M_{b m}+(1-k) M_{b m} e^{-r \theta}
\end{aligned}
$$

The mass fraction of ash is thus

$$
\begin{aligned}
& M_{a} /_{M(\theta)}=\frac{x M_{u m}}{x M_{u m}+(1-x) M_{u m}+k M_{b m}+(1-k) M_{b m} e^{-r \theta}} \\
& =\frac{1}{1+((1-x) / x)+\left(k M_{b m} \mid x M_{u m}\right)+(1-k)\left(M_{b m} \mid x M_{u m}\right) e^{-r \theta}}
\end{aligned}
$$

$\chi$ has a value of about 0.1 .

Fraction of original material present as biodegradable is

$$
\begin{aligned}
& \frac{M_{b m} \theta}{\left(M_{b m}+M_{u m}\right)(\theta)}=\frac{M_{b m} e^{-r \theta}}{M_{b m} e^{-r \theta}+M_{u m}} \\
& =\frac{M_{b m} e^{-r \theta}}{M_{b m} e^{-r \theta}+(1-x) M_{u m}+k M_{b m}\left(1-e^{-r \theta}\right)} \\
& =\frac{M_{b m} e^{-r \theta} / M_{u m}}{(1-x)+k M_{b m} / M_{u m}+(1-k) M_{b m} / M_{u m} e^{-r \theta}}
\end{aligned}
$$

It is assumed that this ratio will be the same whether expressed in volume, mass or COD units, since the biodegradable and unbiodegradable organic fractions are assumed to have the same density and COD.
$=M_{n m}(k g)$

The fraction of biodegradable material present is

Age distribution of material in the pit is determined by the history of deposition, reaction transformation that consumed or generated it.

This originally unbiodegradable material in the pit will have residence time distribution (RTD) density function

$f_{\mathrm{u}}(\theta)$, where $\theta$ is the age of the material (i.e. the time since it was deposited).

$f_{u}(\tau)$ is defined by:

$f_{u}(\tau)=\frac{d F_{o u}(\tau)}{d(\tau)}$

where $F_{\text {ou }}(\tau)$ is the fraction of originally unbiodegradable material at time, $\mathrm{t}\left(\mathrm{kgd}^{-1}\right)$ which

has age $\mathrm{t}<\tau$.

The total mass of the unbiodegradable material is given by:

$M_{u o}(T)=\int_{o}^{T} R_{a u}(t) d t$

where $R_{a u}(t)$ is the rate of addition of unbiodegradable material at time, $\mathrm{t}\left(\mathrm{kgd}^{-1}\right)$, and it is

the time the pit started filling. The RTD function $F_{\text {ou }}(\tau)$ is then given by:

$F_{o u}(\tau)=\frac{\int_{o}^{\tau} R_{a u}(t) d t}{\int_{o}^{T} R_{a u}(t) d t}$

If the rate of addition is constant,

$R_{a u}(t)=R_{a u} t \quad$ and

$M_{u}(T)=M_{u} T$

$F_{\text {ou }}(\tau)=\tau / T$

and $\quad f_{u}(\tau)=\frac{1}{T}$

Equation 3.1 implies that a mass $\mathrm{dM}_{\text {uo }}$ of originally unbiodegradable material of age

between $\tau$ and $\tau+\mathrm{d} \tau$ will be associated with a mass $\phi(\tau) d M_{u o}$

Thus, the total mass of material in the pit is:

$M(T)=\int_{o}^{T} R_{a u}(\tau) . \emptyset(\tau) d \tau$

For a constant addition rate this becomes:

$M(T)=R_{a u} \cdot T \int_{o}^{T} f_{u}(\tau)=R_{a u} \cdot T \int_{o}^{T} 1 / T . \emptyset(\tau) d t$

$=$

$R_{a u} \int_{o}^{T}\left[1+\left(k M_{b m} / M_{u m}\right)+(1-k)\left(M_{b m} /_{M_{u m}}\right) e^{-r \tau}\right] d \tau$ (3.15)

$M(T)=$

$R_{a u}\left[\left(1+\left(k M_{b m} /_{M_{u m}}\right)\right) T+\right.$

1-kMbmMum1-e-rTr

Equation 3.16 applies to the entire content of the pit at age, $\mathrm{T}$ since the pit started filling, and can be used to calculate the height of faecal matter in the pit given pit dimensions when the pit has been in use for given time, T. Pn order to establish a profile of age with level below the surface, consider the mass with age between $\mathrm{t}$ and $\mathrm{T}$ where $0<t<$ $T$ :

$$
\begin{aligned}
& M(t, T)=R_{a u} \cdot T \int_{t}^{T} f_{u}(\tau) . \emptyset(\tau) d t \\
& = \\
& R_{a u}\left[\left(1+k M_{b m} / M_{u m}\right)(t, T)+\right. \\
& 1-k M b m M u m 1-e-r T r
\end{aligned}
$$


Since material of age, $\mathrm{T}$ corresponds to the bottom of the pit, Equ. (3.17) can be used to calculate the level of material in the pit of age, $t$, knowing the dimensions of the pit.

Thus the level of faecal sludge in the pit of age $t$ can be calculated as follows:

Mass of sludge $=M(t, T)$

Mass of sludge $M(\mathrm{~kg})$ of known age in a pit of cross sectional area, A $\left(\mathrm{m}^{2}\right)$ and height, y $(\mathrm{m})$ and density, $\rho$ $\left(\mathrm{kg} / \mathrm{m}^{3}\right)$ is $M(t, T)=A_{\gamma \rho}$

Therefore, the level of sludge of a given age in the pit can be calculated using:

$y=\frac{M(t, T)}{\rho A}$

$=\frac{R_{a u}\left[\left(1+k M_{b m} / M_{u m}\right)(T-t)+(1-k)\left(M_{b m} / M_{u m}\right)\left(\left(e^{-r t}-e^{-r T}\right) / r\right)\right]}{\rho A}$

(3.18)

where $A$ is the cross sectional area of pit in $\mathrm{m}^{2}$, $\mathrm{y}$ is the depth of the faecal sludge in metre and $\rho$ is the density of the faecal material in $\mathrm{kg} / \mathrm{m}^{3}$.

The fraction of biodegradable material at this age can be calculated using Equ. (3.6).

When $\mathrm{T}-\mathrm{t}=0, \mathrm{y}=\mathrm{h}$, Equation 3.17 reduces to
$h=\frac{R_{a u}(1-k) M_{b m} / M_{u m}\left(e^{-r t}-e^{-r T}\right)}{\rho A r}$ or

$h=k_{1}\left(e^{-r t}-e^{-r T}\right)$

where $k_{1}=\frac{R_{a u}(1-k) M_{b m} / M_{u m}}{\rho A r}$

$\frac{h}{k_{1} e^{-r t}}=\frac{1-e^{-r T}}{e^{-r t}}$

$\mathrm{h}, \mathrm{k}_{1}$ and $\mathrm{T}$ are variables.

$h=k_{1} e^{-r T}-\frac{k_{1} e^{-2 r T}}{e^{-r t}}$

$\frac{h}{k_{1}}=\frac{1}{e^{y T}}-e^{-2 r T} e^{y t}$

$y=b-a x$ where $a=e^{-2 r T} ; x=e^{r t}$ and $b=k_{1} e^{-r T}$. If

$t=0$,

$b=k_{1} e^{-r T}$

$a=k_{1} e^{-2 r T}$

$\frac{a}{b}=e^{-r T}$

$\operatorname{In}(a / b)=-r T \Rightarrow r=(1 / T) \ln (a / b)$

Below are COD Values (mg/g) obtained from faecal sludge sampled from the 6 different layers of same pit. The data were used to plot Figure 3.1 from where the value of $r$ (the rate constant) was computed.

Table 2: Model Parameters obtained Using data from one Pit latrine

\begin{tabular}{|l|l|l|l|c|c|c|}
\hline Pit & S/N & $\begin{array}{l}\text { Mean COD } \\
\text { values }\end{array}$ & $\begin{array}{l}\text { Mum (unbiodegraded } \\
\text { portion) }\end{array}$ & $\begin{array}{l}\mathrm{M}_{\mathrm{bm}} \text { (biodegraded } \\
\text { portion) }\end{array}$ & $\begin{array}{l}\mathrm{M}_{\mathrm{bm} /} \\
\text { Mum }\end{array}$ & $\begin{array}{l}\mathrm{k}_{1}=\mathrm{R}_{\mathrm{au}}(1-\mathrm{k}) \mathrm{M}_{\mathrm{bm}} / \mathrm{M}_{\underline{\mathrm{um}}} \\
\rho \mathrm{Ar}\end{array}$ \\
\hline Pit 1 & $\begin{array}{l}\text { Surface } \\
\text { layer }\end{array}$ & 850 & 143 & 707 & 4.94 & $0.0004 / \mathrm{r}$ \\
\hline & $0.2 \mathrm{~m}$ & 485 & 143 & 342 & 2.39 & $0.0002 / \mathrm{r}$ \\
\hline & 0.4 & 558 & 143 & 415 & 2.90 & $0.00023 / \mathrm{r}$ \\
\hline & 0.6 & 222 & 143 & 79 & 0.55 & $0.00004 / \mathrm{r}$ \\
\hline & 0.8 & 141 & 143 & 2 & 0.03 & $0.000002 / \mathrm{r}$ \\
\hline
\end{tabular}

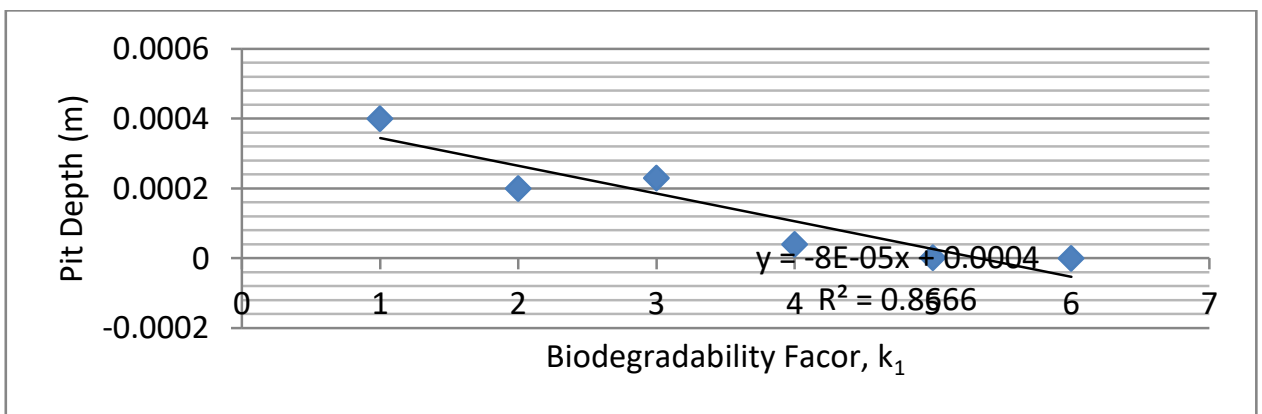

Figure 3.1: Variation of Pit Depth with Biodegradability Factor

$\ln k_{1}=\frac{\ln R_{a u}(1-k) M_{b m} / M_{u m}}{\rho A r}$

Slope $=\frac{4.03}{1}=-4.03 r=a$

Intercept $=3.40=b$

$\mathrm{y}=-0.403 \mathrm{rx}+0.34$

But $r=(-1 / T) \ln a / b$

$=-1 / 18(\ln a-\ln b)$

$=-1 / 18(\ln (-4.03 r)-\ln 3.4)$

$-18 r=\ln (-4.03)+\ln r-\ln 3.4=-1.224+0.018+$

$\ln r$

$18 r+\ln r=1.206$
Calibrating gives $\mathrm{r}=0.0096 /$ day.

Therefore, $h=\frac{R_{a u}(1-k) M_{b m} / M_{u m}\left(e^{-r t}-e^{-r T}\right)}{\rho A r}$

$$
=\frac{R_{a u}(1-k) M_{b m} / M_{u m}\left(e^{-0.0096 t}-e^{-0.0096 T}\right)}{0.0096 \rho A}
$$

This model can be generally used to determine the level of faecal sludge in the pit latrine at any time during its useful lifespan for a particular household based on known population, estimated sludge volume per day, length and frequency of usage.

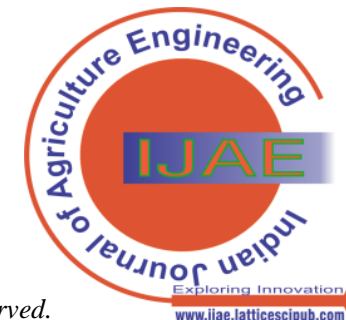




\section{Modeling the Filling Rate of Faeces in Ordinary Pit Latrines}

\section{RESULTS AND DISCUSSIONS}

\subsection{Predicted Pits Filling Rates using known Parameters}

BOD, COD and VS data obtained from laboratory analysis of faecal matter sampled from pit latrines $1-3$ were used to predict filling rates in the pit latrines. The model used in the prediction was derived earlier and is stated here once more. $h=k_{1}\left(e^{-r t}-e^{-r T}\right)$ where $\mathrm{k}_{1}=\underline{\mathrm{R}_{\mathrm{au}}}(1-\mathrm{k}) \mathrm{M}_{\underline{\mathrm{bm}}} / \mathrm{M}_{\underline{\mathrm{um}}}$ and $\mathrm{x}=e^{-r t}-e^{-r T}$. Therefore, $\mathrm{h}=\mathrm{k}_{1} \mathrm{x}$.

t ranged from $0,2,4,6,8$ to10 years from surface to bottom of pit and $\mathrm{T}$ was 10 years. At the surface, $\mathrm{t}$ is 0 and at the bottom, $\mathrm{T}$ is 10 years. Using $\mathrm{k}$ as $0.1, \mathrm{R}_{\mathrm{au}}$ as $0.7, \mathrm{~A}$ as $4.0 \mathrm{~m}^{2}$, $\mathrm{r}$ as 0.0096 per day and $\rho$ as $2500 \mathrm{~kg} / \mathrm{m}^{3}$ for Pit 1 ; $\mathrm{k}$ as 0.1 , Rau as $0.7, \mathrm{~A}$ as $4.0 \mathrm{~m}^{3}$, $\mathrm{r}$ as 0.0096 per day, $\rho$ as $2500 \mathrm{~kg} / \mathrm{m}^{3}$ for Pit 2 and $\mathrm{k}$ as $0.1, \mathrm{R}_{\text {au }}$ as $0.7, \mathrm{~A}$ as $4.0 \mathrm{~m}^{2}$, $\mathrm{r}$ as 0.0096 per day, $\rho$ as $2500 \mathrm{~kg} / \mathrm{m}^{3}$, predicted filling rates were computed as shown in the Tables 3 .

$\rho \mathrm{Ar}$

Table 3: Predicted Filling Rates of Faecal Sludge in 10 Pit latrines

\begin{tabular}{|r|r|r|r|r|r|c|}
\hline Pit & BOD (m/yr) & COD (m/yr) & \multicolumn{1}{|c|}{ VS (m/yr) } & TS (m/yr) & $\mathrm{R}_{\mathrm{au}}(\mathrm{Kg} / \mathrm{day})$ & $\begin{array}{l}\text { Predicted filling rate } \\
(\mathrm{m})\end{array}$ \\
\hline 1 & 0.043 & 0.05 & 0.077 & 0.017 & 4.5 & 0 \\
\hline 2 & 0.012 & 0.031 & 0.016 & 0.061 & 1.7 & 0.0075 \\
\hline 3 & 0.083 & 0.036 & 2.457 & 0.023 & 4.5 & 0.0075 \\
\hline 4 & 0.024 & 0.018 & 0.588 & 0.015 & 1.7 & 0.0076 \\
\hline 5 & 0.128 & 0.038 & 1.775 & 0.063 & 5 & 0.0078 \\
\hline 6 & 0.091 & 0.11 & 0.071 & 0.049 & 6 & 0.0124 \\
\hline 7 & 0.206 & 0.04 & 0.063 & 0.044 & 6.5 & 0.01333 \\
\hline 8 & 0.552 & 0.136 & 0.075 & 0.063 & 3.5 & 0.0152 \\
\hline 9 & 0.046 & 0.056 & 0.113 & 0.02 & 3.5 & 0.0088 \\
\hline 10 & 0.067 & 0.053 & 0.104 & 0.021 & & 53 \\
\hline
\end{tabular}

\subsubsection{Modeling Pit Filling rate Considering Shape Factor}

Existing filling rate model by Ugwu (2015) which did not consider pit shape factor shows that:

$h=k_{1} \cdot \mathrm{x}=\frac{R_{a u}(1-k) M_{b o} / M_{u o}\left(e^{-r t}-e^{-r T}\right)}{\rho A r}$ where

$k_{1}=\frac{R_{a u}(1-k) M_{b o} / M_{u o}}{\rho A r}$ and $\mathrm{x}=\left(e^{-r t}-e^{-r T}\right)$ where $\mathrm{h}$ is the level of filling in metre, $\mathrm{R}_{\mathrm{au}}$ is the rate of addition of faecal matter into the pit latrine in $\mathrm{kg}, \mathrm{r}$ is the rate constant in day $^{-1}$, $\mathrm{k}$ is the proportion of the mass of each $\mathrm{kg}$ of biodegradable material degrades to form mass of new unbiodegradable material, $\mathrm{M}_{\mathrm{bo}}$ is the mass of original biodegradable material in $\mathrm{kg}, \mathrm{M}_{\mathrm{uo}}$ is the mass of unbiodegraded material at the end of the biodegradation process in $\mathrm{kg}$, $\mathrm{A}$ is the cross sectional area of the pit latrine in $\mathrm{m}^{2}, \mathrm{t}$ and $\mathrm{T}$ are the filling times within particular pit depth specified in years and $\rho$ is the density of faeces in $\mathrm{kg} / \mathrm{m}^{3}$. Now, considering the shape factor, the above expression becomes:

hsf $=k_{1}\left(e^{-r t}-e^{-r T}\right)=k_{1}$ x. Now $k_{1}=\frac{R_{a u}(1-k) M_{b o} / M_{u o}}{\rho A s f . r}$ and $\mathrm{x}=\left(e^{-r t}-e^{-r T}\right), A s f$ is the cross sectional area considering shape factor while $\mathrm{A}$ is the cross sectional area of the normal pit.

Effective area, $\mathrm{A}_{\mathrm{ef}}=A x s f=0.79 A$ where the shape factor is 0.79 . Therefore,

$h s f=k_{1} \cdot \mathrm{x}=\frac{R_{a u}(1-k) M_{b o} / M_{u o}\left(e^{-r t}-e^{-r T}\right)}{0.79 A \cdot \rho r}$
Also $y=M(t, T) / \rho A$

$=\frac{R_{a u}\left[\left(1+k M_{b o} / M_{u o}\right)(t, T)+(1-k) M_{b o} / M_{u o}\left(\left(e^{-r t}-e^{-r T}\right) / r\right)\right]}{0.79 \rho A r}$,

This model can be used particularly for the faecal filling rate in any specified pit shape using the pit shape factor as against the afore-derived general filling rate model.

4.1 Comparison of the Pits Filling Rates Observed in Terms of Faecal Parameters(general model).

In order to obtain some level of idea of pit filling rate using measured parameters, there was need to look critically at the behavior of these parameters in each pit latrine. Consequently, BOD, COD VS and TS have been used to determine this since they give better knowledge of the biodegradation process occurring in the pits.

4.1.1 Comparison of the Pits filling rates observed in the analyses using BOD Data(general model).

It is observed that in Figure1, Pit 8 with population of 8 people in the household has the highest filling rate of $0.5 \mathrm{~m} / \mathrm{yr}$ when compared with others that are below $0.2 \mathrm{~m} / \mathrm{yr}$. This might be as a result of bad user-behaviour of indiscriminate dumping of solid wastes into the pits.

Next are pits 3 and 7 above $0.10 \mathrm{~m} / \mathrm{yr}$. The rest of the pits have filling rates below $0.1 \mathrm{~m} / \mathrm{yr}$ t. It is an evidence of homogeneity in pit contents due to good user behaviour. These pits are likely to serve the users for a very long time before filling up. BOD contributed moderately to the filling rate of pit latrines.

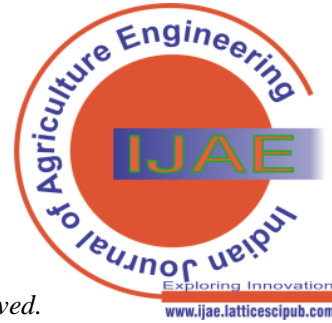




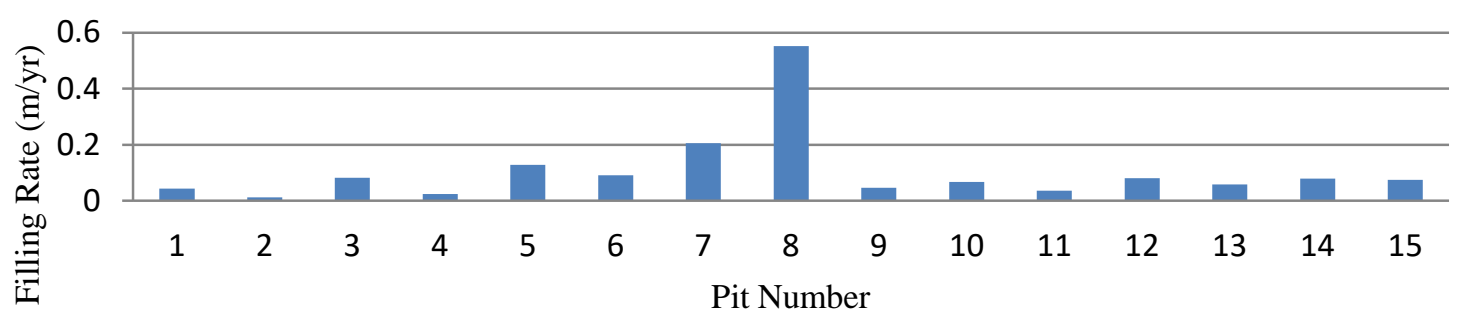

Figure 1: Comparison of Pits Filling Rates in terms of BOD

4.1.2 Comparison of the Pits filling rates observed in the analyses using COD Data (general model).

Figure 2 compared the filling rates of the faecal sludge in the 15 pit latrines. Pits 1, 6, 8, 9, 10 and 14 exhibited filling rates above $0.05 \mathrm{~m} / \mathrm{yr}$. Pit 8 has the highest filling rate followed by Pits 6 and 14. The high filling rates in pits 6, 8 and 14 may be attributed to the usage pattern of the pits such as waste dumping limiting biodegradation process. Filling rates in the other pits ranged between $0.02 \mathrm{~m} / \mathrm{yr}$ to below $0.06 \mathrm{~m} / \mathrm{yr}$. These were due to so many factors limiting the filling rates including user behavior, faecal sludge composition, soil characteristics, ground conditions and microbial activities. On the whole, COD contributed minimally to the filling rate of pit latrines, with the highest less than $0.14 \mathrm{~m} / \mathrm{yr}$ and with preponderance of the pits having filling rates less than $0.06 \mathrm{~m} / \mathrm{yr}$.

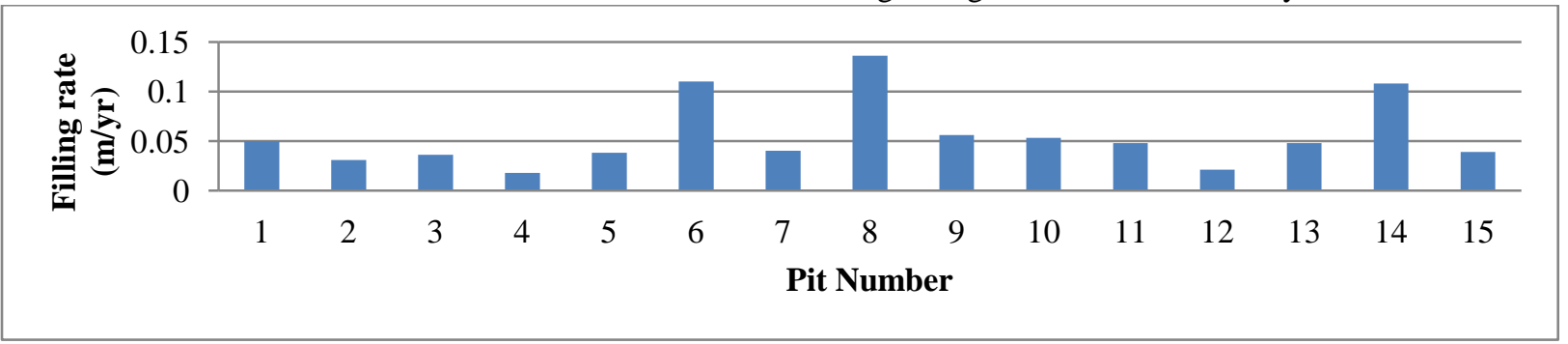

Figure 2: Comparison of Pits Filling Rates in terms of COD

4.1.3 Comparison of the Pits Filling Rates Observed in the Analyses Using Volatile Solids Data (general model). Figure 3 showed the comparison of filling rates of the different pits. Pits 3 and 5 exhibited high filling rates above $1.75 \mathrm{~m} / \mathrm{yr}$. This was an indication that the pits were not used for the purpose of faecal disposal only but also for the dumping of solid wastes collected from the households. Pit
4 has a filling rate of about $0.6 \mathrm{~m} / \mathrm{yr}$. Eighty percent (80\%) of the pits have filling rates below $0.5 \mathrm{~m} / \mathrm{yr}$ and were indication of good pits due to the usage pattern by the households concerned. Pit 3 had the highest filling rate of $2.47 \mathrm{~m} / \mathrm{yr}$ while Pit 5 had $1.75 \mathrm{~m} / \mathrm{yr}$ filling rate. From these facts, volatile solids contributed so much to the filling rate of pit latrines.

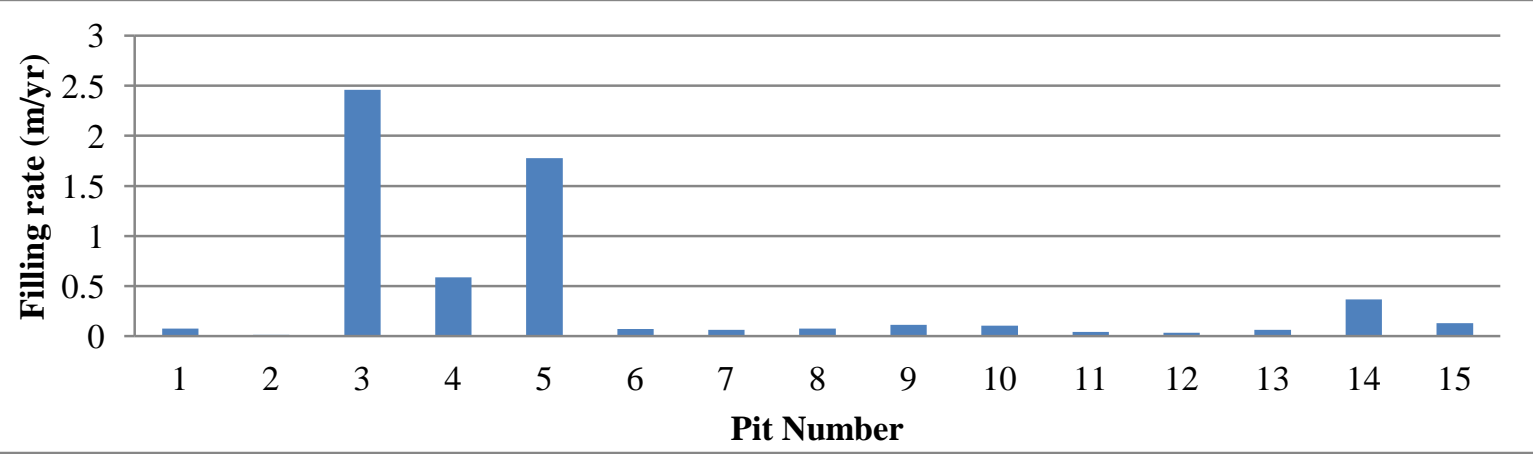

Figure 3: Comparison of Pits Filling Rates in terms of Volatile Solids.

4.1.4 Comparison of the Pits Filling Rates Observed in the Analyses Using Total Solids Data (general model).

Figure 4 showed the filling rates of the 15 pits at a glance. Pits 2, 5, 8 and 14 have filling rates above $0.052 \mathrm{~m} / \mathrm{yr}$ while pits $3,6,7,10,11$ and 15 have filling rates ranging from
$0.02 \mathrm{~m} / \mathrm{yr}$ to below $0.05 \mathrm{~m} / \mathrm{yr}$. Variations in filling level were due pit contents including sweepings from the households and soil characteristics. Total solids content appeared to contribute little to the pit filling rates where biodegradation was high and vice versa.

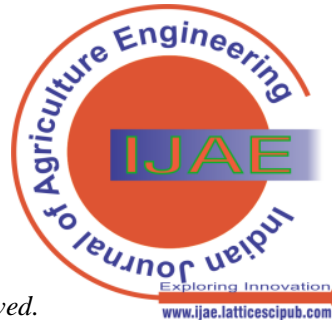




\section{Modeling the Filling Rate of Faeces in Ordinary Pit Latrines}

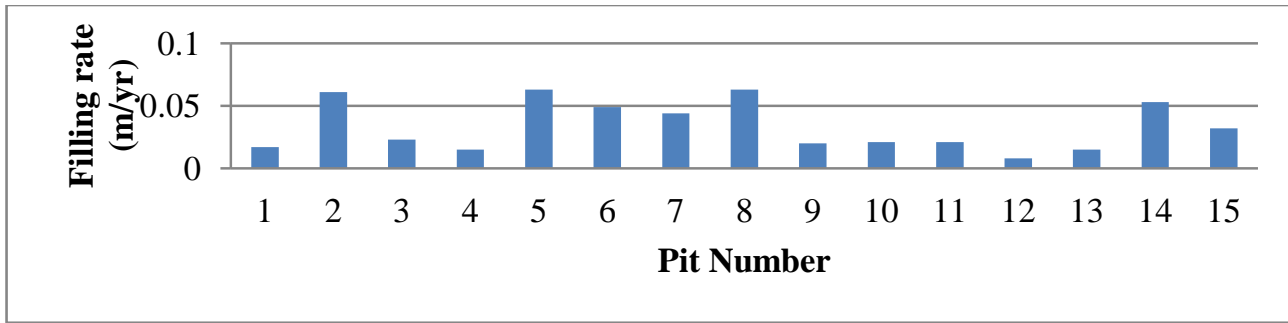

Figure 4: Comparison of Pits Filling Rates in terms of Total Solids

4.1.5 Comparison of Actual Filling Rate in Pit Latrines with Those of COD, BOD, VS and TS (general model)

Figure 5 showed the comparison of actual filling rates with those obtained in terms of COD, BOD, VS and TS. From the Figure, VS had the highest filling rate followed by BOD. Next was that of COD and the TS. The least was the actual filling rate. However, TS is not a good parameter to assess the filling rate of pit latrines due to its low biodegradability. Similarly, BOD cannot also be used to assess pit filling rate since it is aerobic and is a surface phenomenon. COD which is anaerobic and occurred at lower layers of the pit latrine was therefore used to predict better filling rate.

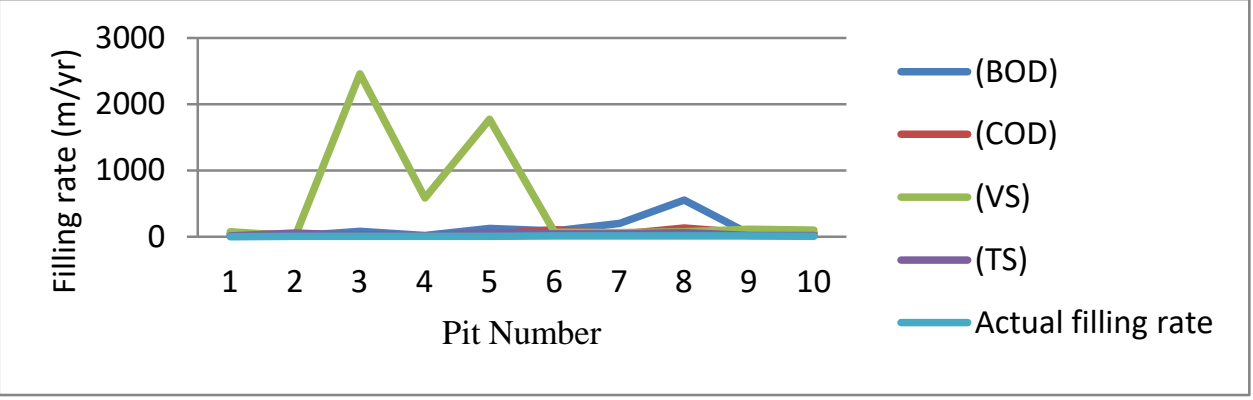

Figure 5: Comparison of Filling Rates in Pit latrines

\subsection{Calibration of Actual and Predicted Pits filling rates} in Terms of Parameters

Figure 6 showed the calibration of actual filling rate with those predicted using sludge parameters namely COD,
BOD, VS and TS. For the Actual filling rate, the coefficient of correlation was 0.588 and of course the highest. This was followed by that of the COD with value 0.172 , then BOD with value 0.143 and finally that of TS with zero.

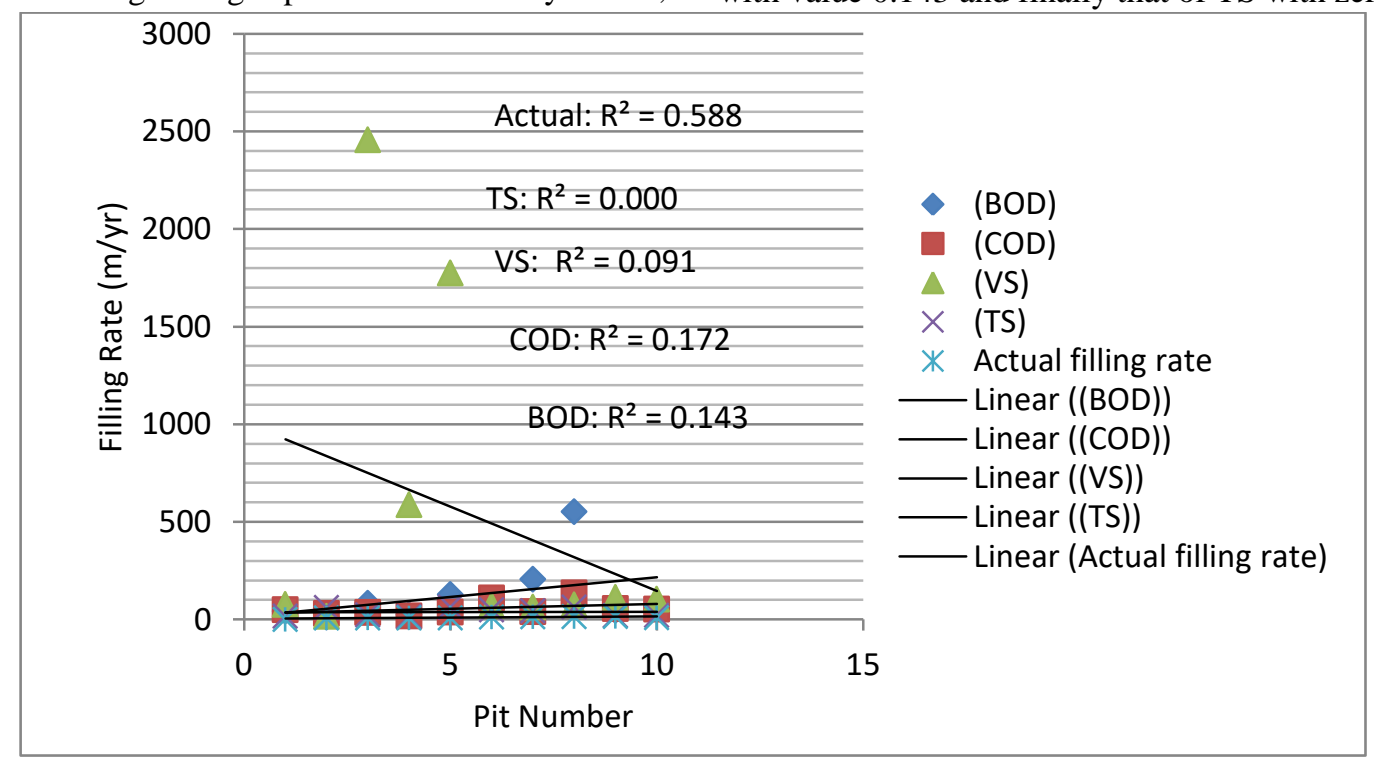

Figure 6: Calibration of Actual and Predicted Filling rates in Pit Latrines

4.2 Comparison of Existing General Filling Rate model with Derived model (with shape factor).

Figure 1a showed the variation of the pit filling rate with filling time for the square pit latrine based on existing model derived model with shape factor considered. The difference between the filling rate in the two cases were indicated. The derived filling rate of the faeces in the pit with shape factor was higher than those of the existing models. As the pit filled, dead corners developed due to the clogging of the pit walls by faeces. Consequently, there was reduction in the area available for infiltration into the surrounding soil by a factor of 0.79 thereby increasing the filling rate of faeces in the pit.

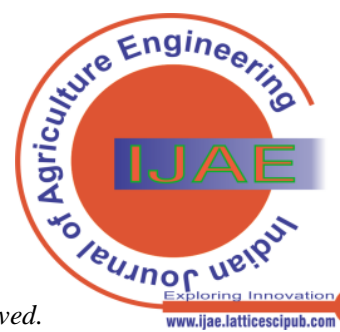


This invariably reduced its lifespan. Figure 1b showed the variation of the pit filling rate with the filling time for the circular pit considering both the existing and the new models incorporating the shape factor. There was no difference in the filling rate in the case of the circular pit since the shape factor was unity. The lifespan of the pit was also not affected. Figure 1c showed the variation of the pit filling rate with the filling time for the rectangular pit latrine considering both models. The filling rate of the faeces in the pit in using derived model was higher than in the case existing model. As the pit filled, dead corners developed due to the clogging of the pit walls by faeces just like in the case of square pit. Consequently, there was reduction in the area available for faecal infiltration into the surrounding soil by a factor of 0.79 thereby increasing the filling rate. This also reduced the lifespan of the pit.
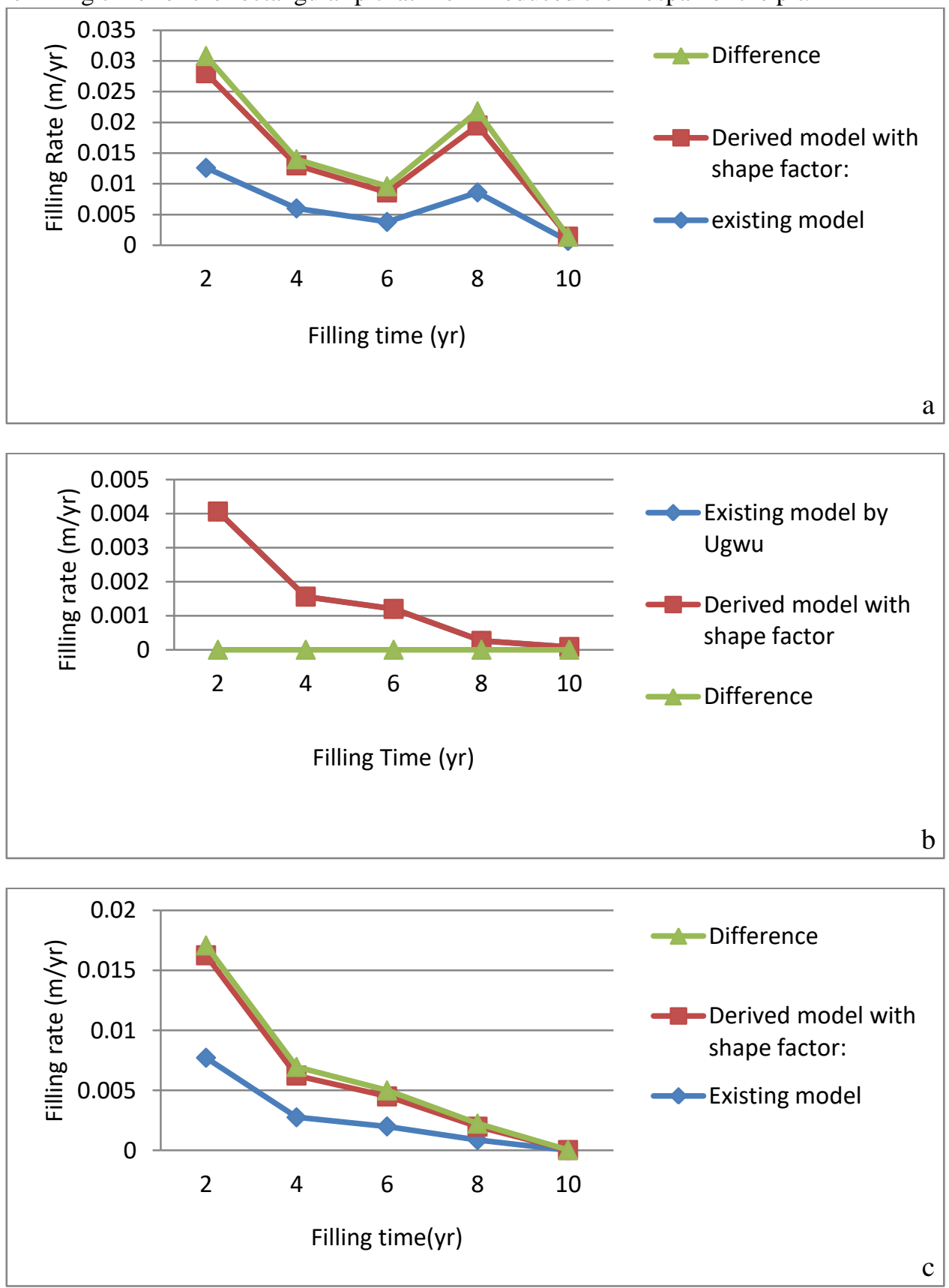

Figure 1: Variation of filling rate with filling time in (a) square (b) circular (c) rectangular pit latrines.

4.3 Comparison of Pit Volumes using Existing Models and Derived Models.

Figures 2 (a, b, c) showed the variation of pit volume with pit number for the square, circular and rectangular pit latrines. From Figures 2a and 2c, the derived pit volumes using existing model were higher than those of the derived models with shape factor for both the square and rectangular pits latrines. This was due to the development of dead corners arising from clogging by faecal matter in the pit latrine walls. Figure $2 b$ showed no change in the circular pit volumes in both models since the shape factor for circular pit is unity. 


\section{Modeling the Filling Rate of Faeces in Ordinary Pit Latrines}
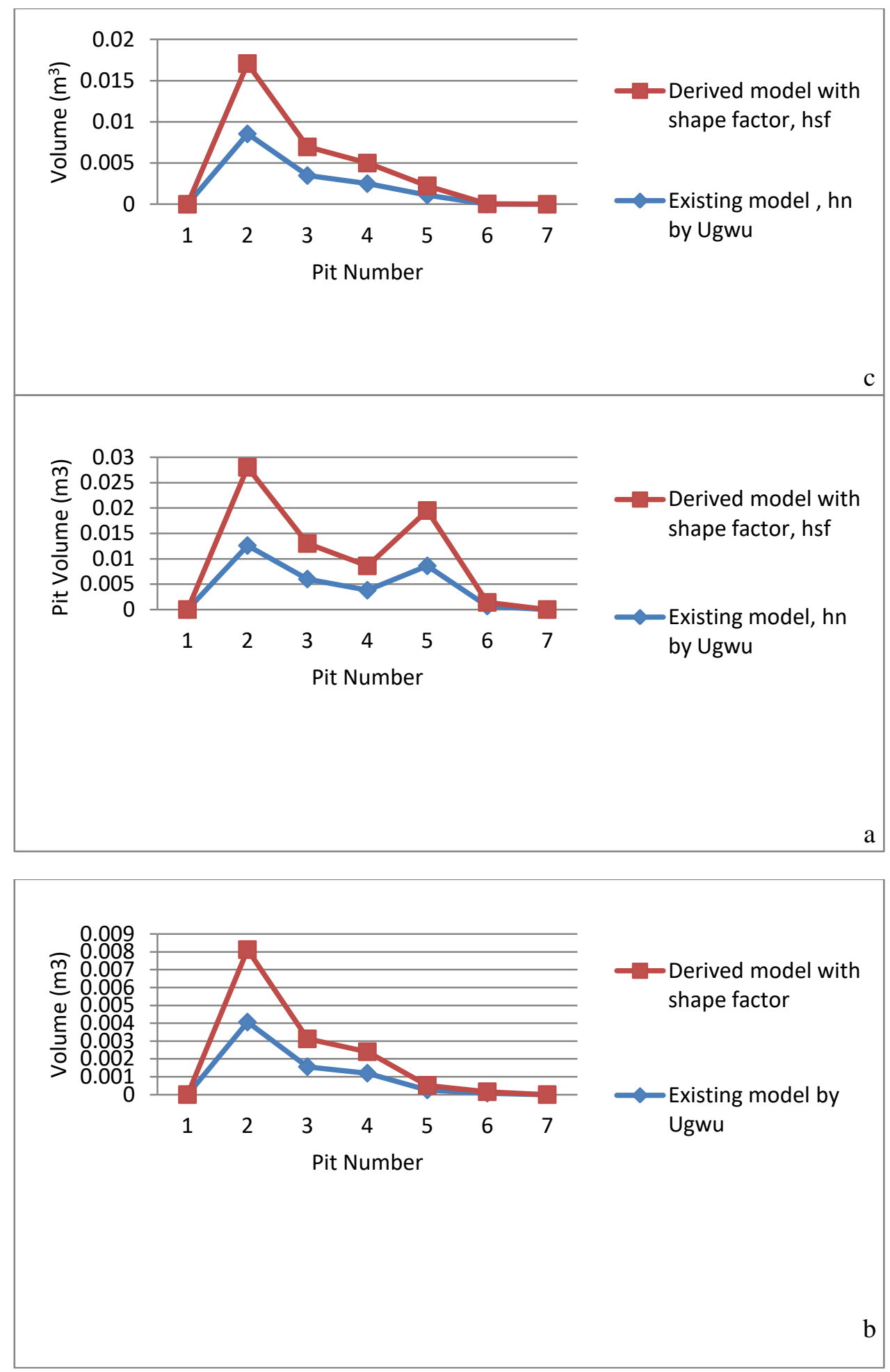

Figure 2: Effect of shape factor on pit volume for the (a) square (b) circular, and (c) rectangular pits under existing and derived models.

\subsection{Results of Calibration}

Figures 3-5 showed the calibration of existing models and derived models that incorporated shape factors for the square, circular and rectangular pit latrines. The derived model correlated very well with the existing models. For the three pit latrines, the correlation coefficients for the square pit latrines were 0.996 for the Ugwu model, 0.996 for that of Oluwafemi, 0.991 for the CASSAD model and 0.992 for the derived model in Figure 3. In the case of circular pit latrine in Figure 4, the value was 0.966 for Ugwu model, 0.994 for Oluwafemi model, 0.994 for the CASSAD model and 0.938 for the derived model. For the rectangular pit in Figure 5, the value was 0.996 for Ugwu model, 0.996 for Oluwafemi, 0.966 for CASSAD and 0.997 for the derived model with shape factor.

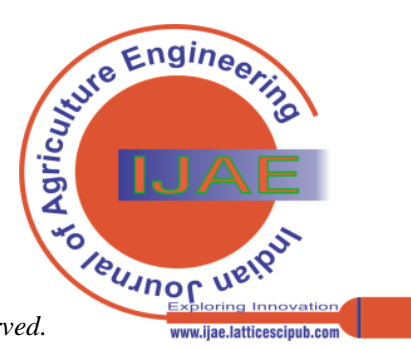



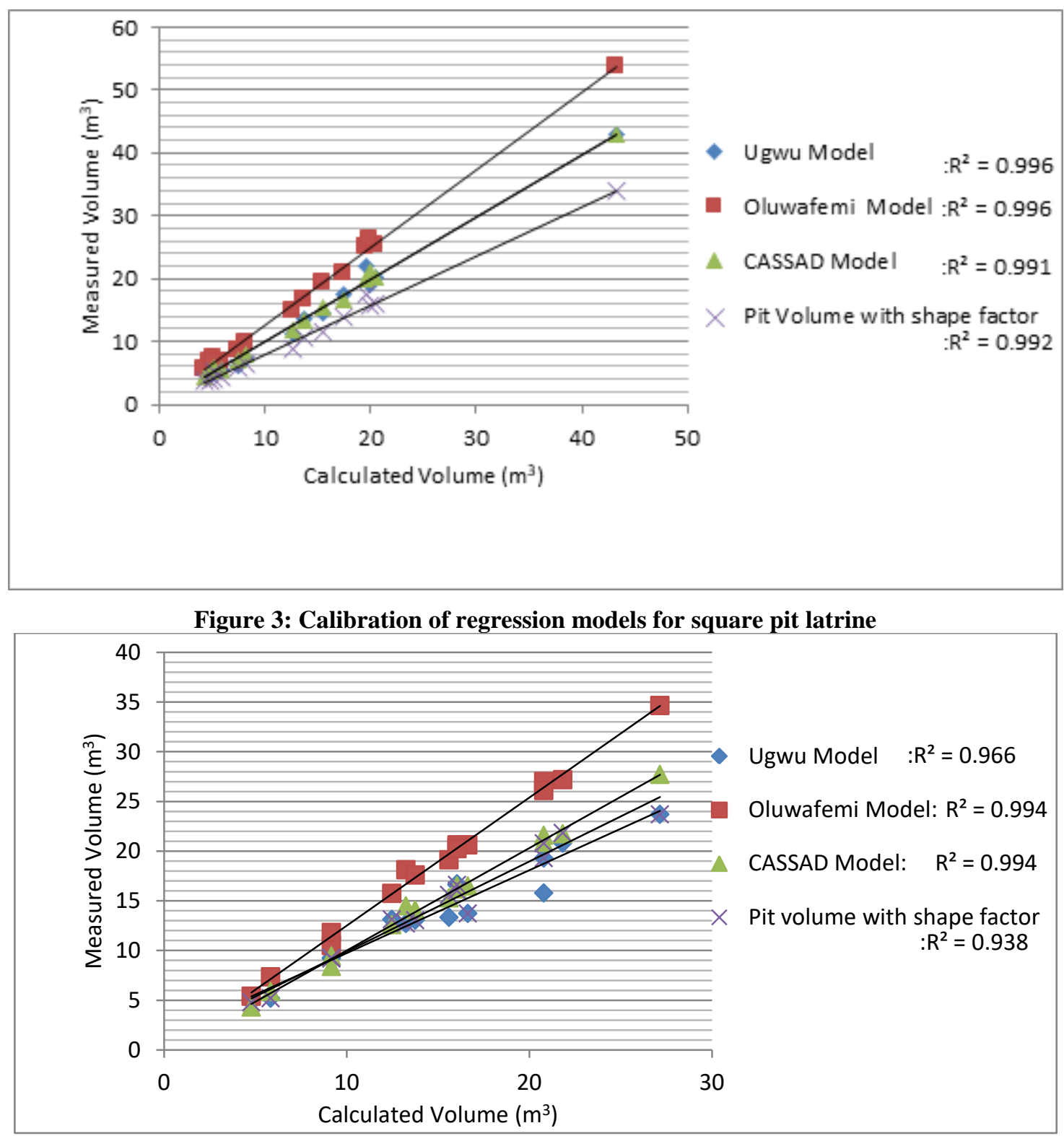

Figure 4: Calibration of regression models for circular pit latrine

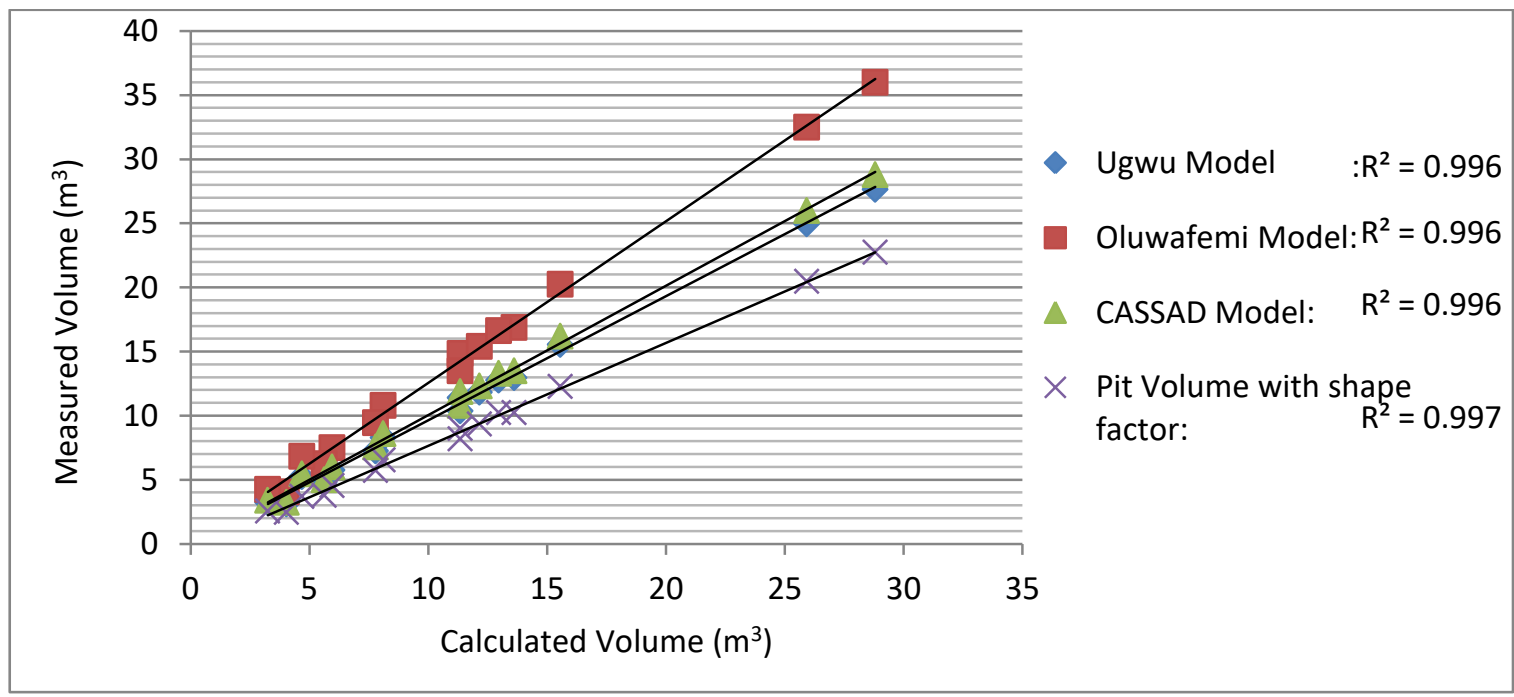

Figure 5: Calibration of regression models for rectangular pit latrine

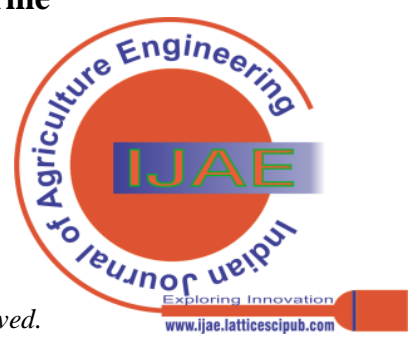




\section{Modeling the Filling Rate of Faeces in Ordinary Pit Latrines}

\subsection{Results of Verification}

The models derived were verified using filed data. The coefficient of verification for the square, circular and rectangular pit latrines were 0.97, 0.98 and 0.99 respectively. Figure 6 showed the relationship between the derived values and the actual values. Both the actual and derived values exhibited very highly correlation coefficients. The correlation coefficient, $\mathrm{R}^{2}$ for the rectangular pit (Figure 6c) was the highest with the value, 0.990 followed by the circular pit (Figure 6b) with the value, 0.959 and lastly the square pit (Figure 6a) with the value 0.939. This showed that the data collected from the field for were reliable.
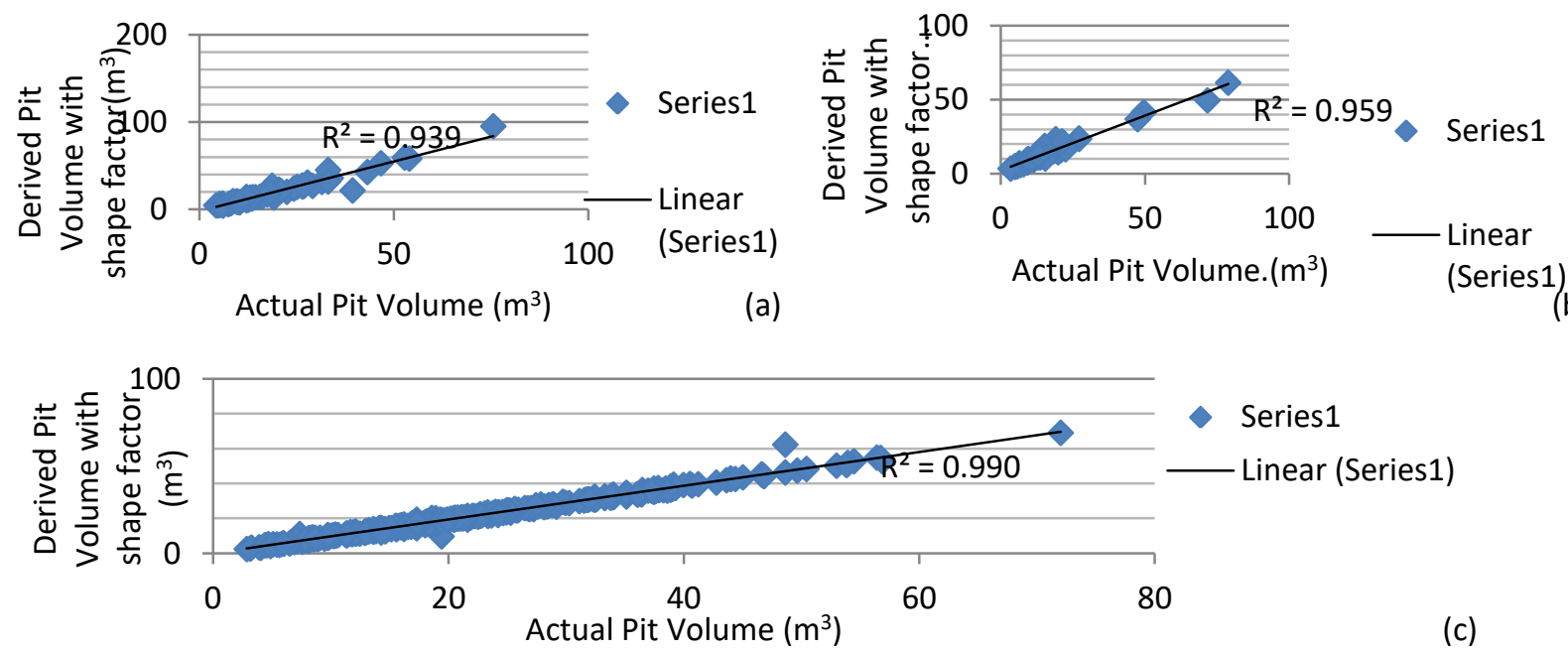

Figure 6: Correlation between Actual and Derived Pit Volumes for (a) square (b) circular (c) rectangular pit

4.6 Percentage Change in Filling rate in both the Existing and derived models.

Figure 7 compared the models for the filling rates in the various pit shapes. The percentage variation in derived filling rate in the case of rectangular pit was higher than those of the other two pits. The initial value in the case of rectangular pit was less than that of the square pit. This might be due to initial greater microbial activities in the square pit than in the rectangular pit. For the square pit latrine, the filling rate exhibited triple scenarios, decreasing from initial value of $22.22 \%$ to $16.67 \%$, increased to $26.74 \%$ and finally decreased drastically to a null value. That of the circular pit showed no change in pit filling rate throughout the process in both the existing and derived models. The percentage variation in filling rate in the case of the rectangular pit exhibited triple scenarios, increasing from initial value of $10 \%$ to a value of $26 \%$, decreased to $25 \%$ and then increased to a final value of $50 \%$ which was the highest observed in the analysis. As the filling time increased, the filling rate from existing model was lower than that from the derived model resulting to the increase in filling rate for both the square and the rectangular pit latrines. Variation of filling rate was due to the degree of clogging of the soil pores along the pit walls limiting infiltration into the surrounding soil. Consequently, the lifespan of the pits reduced accordingly.

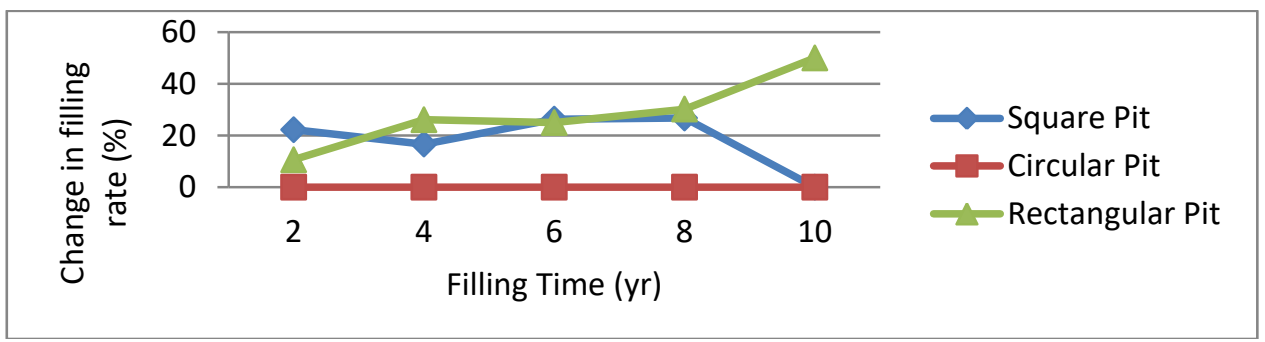

Figure 7: Percentage change in filling rate in 3 different pit shapes using derived models.

V.

\section{CONCLUSIONS AND RECOMMENDATIONS}

\subsection{Conclusions.}

A study on the effect of pit shape on the effective volume and filling rate of faeces in pit latrine of different shapes was carried out. Models incorporating shape factors for the design of different pit shapes were derived. The actual pit volume, the pit volume arising from existing models by Ugwu (2015), Oluwafemi (1984), and CASSAD (2005) correlated very highly with the newly derived model.
Comparison of the actual field volume, volume using existing models, and the volume obtained from the derived model showed that the pit volume was lowest with derived model in both the square and rectangular pits but remained the same in the case of circular pits. The actual pit volumes obtained from the field were higher than both of the existing and derived models.

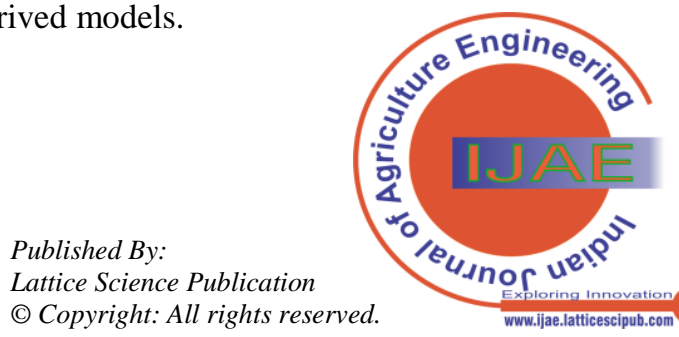


Dead corners developed during pit usage thereby reducing effective cross sectional areas of the square and rectangular pits by 0.79 . The pit filling rates in both the square and rectangular pits increased by $26.5 \%$ due to the effect of shape factors leading to the reduction of the lifespan of such pits.

\subsection{Recommendations}

Below are the recommendations made based on this research:

- Models incorporating shape factors should be used in designing pit latrines of different shapes to enable users know the exact filling time..

- $\quad$ Pit filling time of one or more different shapes of latrine should be practically studied in the field to correlate it with derived models (with and without shape factor) to further establish the exact difference between them and thus validate the models.

- To improve the situation, there is need to develop, disseminate and enforce pit latrine technology specifications and service standards for different target groups and to sensitize them on the need for hygienic latrines.

\subsection{Conclusions and Recommendations}

\subsection{Conclusions}

This research for the derivation of models for pit filling rate has been carried out. The biodegradability of the pit sludges have also been established based on some physico-chemical and biological characteristics of the faecal sludges namely the BOD, COD, volatile solid and total solids. Filling rate of faecal sludge is a function of the nature of pit content and microbial activities taking place in the pit latrine which will bring about biodegradation of faeces apart from soil characteristics and ground conditions.

From the above study, the following conclusions were reached:

- Model for the fill up rate has been developed, verified and calibrated using data obtained from the analyses of faecal sludges sampled from 15 pit latrines in the study area.

- Low filling rate was exhibited by COD and total solids contents. The highest came from volatile solids to the tune of $2.47 \mathrm{~m} / \mathrm{yr}$ while BOD had the filling rate of $0.55 \mathrm{~m} / \mathrm{yr}$.

- With low filling rate value, COD is a better measure of filling rate than the other three parameters since this will lead to longer lifespan of pits

- The high variability of the observed results was due to poor user-behaviour, the nature of food consumed by households and available conditions in the pit latrines.

\subsection{Recommendations}

The following recommendations, arising from the outcome of this study, were made:

- Proper education of users is of paramount importance to ensure that pit latrines are put into maximum use. This will eliminate problems associated with pit latrines including high filling rates.

- Another study should be conducted on pit sludge at households level to find out the time it will take the pits to fill knowing the dimensions, user population and soil parameters. This will involve daily monitoring of the drop down of the sewage until it stabilizes.

\section{REFERENCES}

\section{Journal Papers}

1. APHA (1998) Standard Methods for the Examination of Water and Wastewater. 20 ${ }^{\text {th }}$ Edition. American Public Health Association.

2. Bhagwan JN, Still D, Buckley C, Foxon K. (2008). Challenges with Up-Scaling Dry Sanitation. Technologies. Water Sci Technol. 58(1); 21-27 WILSON, H.E (1978). Personal Communication. Institute of Geological Sciences, London. [CrossRef]

3. Coteral, J.A. and Dan, P. Norris (1979). Septic Tank Systems. Journal of the Sanitary Engineering Division. Proceedings of the American Society of Civil Engineers.

4. Foxon, K. and Buckey, C.A (2008). Scientific Support for the Design and Operation of Ventilated Improved Pit latrines. KS/1630/08. Water Research Commission in Press

5. Mara, D.(1984). 'The Design of VIP Latrines', TAG Technical Note. World Bank. Washington DC.

6. Nwaneri, C.F (2008). Biological Degradation Processes Within A Pit Latrine Pollution Research Group, Department of Biological and Conservation Sciences, University of KwaZulu-Natal, Durban 4041.

7. Grady C, Daigger G, Lim H, eds.(1999). Biological Wastewater Treatment. New York, USA. Marcel Dekker; edition n, ed.

\section{Chapters in Books}

8. Couderc AA, Foxon K, Buckley CA, et al.(2008). The Effect of Moisture Content and Alkalinity on the Anaerobic Biodegradation of Pit latrine sludge. Water Sci. Technol. 58(7); pp.1461-1466. [CrossRef]

9. Bouma J. (1974). New Concepts in Soil Survey Interpretations For OnSite Disposal of Septic Tank Effluent. Soil Science Society of America, Proceedings No. 38, pp. 941-46. [CrossRef]

10. Martin D, Potts L and Heslop V (2003). Reaction Mechanisms in Solid-State Anaerobic Digestion. The Reaction Front Hypothesis. Trans. Inst. Chem. Eng.; 81(B): 171 - 179. [CrossRef]

\section{Thesis}

11. Buckley C, Foxon K, Brouckaert C, et al (2008). Scientific Support for the Design and Operation of Ventilated Improved pit latrines (VIPs) and the Efficacy of Pit latrine Additives. KwaZulu-Natal: Pollution Research Group School of Chemical Engineering University of KwaZulu-Natal. 